\title{
Factors Related with Adiponectinemia in Obese and Normal-Weight Women and with Its Variation in Weight Loss Programs
}

\author{
José Silva-Nunes ${ }^{a, b} \quad$ Ana Oliveira ${ }^{b} \quad$ Leone Duarte $^{c, d}$ \\ Margarida Barradas $^{c}$ Alice Melão ${ }^{b}$ Miguel Brito $^{b} \quad$ Luisa Veiga $^{b}$ \\ ${ }^{a}$ Endocrinology Department, Curry Cabral Hospital - C.H.L.C., ${ }^{b}$ Escola Superior de \\ Tecnologia da Saude de Lisboa, 'Diabetes Department, Portuguese Diabetes Association, \\ dEndocrinology Department, Hospital da Luz, Lisbon, Portugal
}

\section{Key Words}

Obesity · Adiponectin · Adipokines · Lifestyle factors · Weight loss · Bariatric surgery

\begin{abstract}
Objective: To assess different factors influencing adiponectinemia in obese and normalweight women; to identify factors associated with the variation $(\Delta)$ in adiponectinemia in obese women following a 6-month weight loss program, according to surgical/non-surgical interventions. Methods: We studied 100 normal-weight women and 112 obese premenopausal women; none of them was on any medical treatment. Women were characterized for anthropometrics, daily macronutrient intake, smoking status, contraceptives use, adiponectin as well as IL- 6 and TNF- $\alpha$ serum concentrations. Results: Adiponectinemia was lower in obese women $(p<0.001)$, revealing an inverse association with waist-to-hip ratio $(p<0.001 ; r=$ $-0.335)$. Normal-weight women presented lower adiponectinemia among smokers $(p=0.041)$; body fat, waist-to-hip ratio, TNF- $\alpha$ levels, carbohydrate intake, and smoking all influence adiponectinemia $\left(r^{2}=0.436\right)$. After weight loss interventions, a significant modification in macronutrient intake occurs followed by anthropometrics decrease (chiefly after bariatric procedures) and adiponectinemia increase (similar after surgical and non-surgical interventions). After bariatric intervention, $\Delta$ adiponectinemia was inversely correlated to $\Delta$ waist circumference and $\Delta$ carbohydrate intake $\left(r^{2}=0.706\right)$. Conclusion: Anthropometrics, diet, smoking, and TNF- $\alpha$ levels all influence adiponectinemia in normal-weight women, although explaining less than $50 \%$ of it. In obese women, anthropometrics modestly explain adiponectinemia. Opposite to non-surgical interventions, after bariatric surgery adiponectinemia increase is largely explained by diet composition and anthropometric changes.
\end{abstract}


Silva-Nunes et al.: Factors Related with Adiponectinemia in Obese and Normal-Weight Women and with Its Variation in Weight Loss Programs

\section{Introduction}

Adipose tissue is a very dynamic and versatile endocrine organ secreting a large amount of bioactive molecules called adipokines [1]. Adiponectin is one of the most abundant adipokines secreted by adipocytes [2]. It is a protein hormone that circulates in several different size complexes in serum. Its basic unit is a trimer which can assemble to form hexamers, and several of these hexamers can assemble into a high molecular weight (HMW) complex [3]. Located on chromosome 3q27, a susceptibility locus for diabetes and cardiovascular disease, the adiponectin gene encodes a secretory protein expressed exclusively in adipose tissue [4]. Some single nuclear polymorphisms of the adiponectin gene have been identified and may be an additional factor influencing adiponectinemia [5, 6]. Adiponectin is the major adipokine with reported beneficial effects, namely anti-inflammatory and antiatherogenic properties, protecting endothelial cells, inhibiting the proliferation of vascular smooth muscle cells, and suppressing the conversion of macrophages to foam cells [7]. Adiponectin circulating levels are inversely associated with insulin resistance although it is not perfectly determined if hypoadiponectinemia is a cause or consequence of that condition $[8,9]$. Although being a product of the adipose tissue, its levels have been demonstrated to be decreased in obese individuals. That paradoxical situation is not fully explained but seems to be related to the effect of other adipokines, mainly tumor necrosis factor alpha (TNF- $\alpha$ ) [10]. The excessive body fat mass, primarily at the abdominal location, would induce an increase in TNF- $\alpha$ which down-regulates adiponectin synthesis by the adipocytes $[11,12]$. The regular pattern of macronutrient consumption has also been described as a regulating factor for adiponectin circulating levels $[13,14]$. Hypoadiponectinemia is a risk factor for several pathological conditions [15-17]. A strategy that decreases the amount of fat mass would be expected to augment the circulating levels of adiponectin [18]. So, a therapeutic approach aimed to increase plasma adiponectin levels could be beneficial to prevent, control, or reverse conditions such as the metabolic syndrome, type 2 diabetes, high blood pressure, and atherosclerosis.

Although adiponectin circulating levels are reported to be inversely associated with body fat, we aimed to assess the influence of several anthropometric parameters, diet, smoking, use of oral contraceptives as well as interleukin 6 (IL-6) and TNF- $\alpha$ levels on total adiponectin circulating levels in both obese and normal-weight women. Secondarily, we intended to evaluate which of those parameters most closely parallel the variation of adiponectin levels expected to occur during weight loss programs (surgical and non-surgical interventions).

\section{Participants and Methods}

\section{Subjects}

The obese group consisted of 112 obese Caucasian premenopausal women, which attended the obesity outpatient clinic at the Curry Cabral Hospital - C.H.L.C. (Lisbon, Portugal). Their age ranged from 18 to 50 years, and their BMI was $\geq 30 \mathrm{~kg} / \mathrm{m}^{2}$. All of them referred a less than $10 \%$ variation of their body weight in the previous year.

The control (normal-weight) group consisted on 100 Caucasian premenopausal women who either attended to a routine health check or belonged to the health care staff of Curry Cabral Hospital - C.H.L.C. Their age was between 18 and 50 years, and their BMI ranged from 18.5 to $24.9 \mathrm{~kg} / \mathrm{m}^{2}$; all of them referred less than $10 \%$ variation of their body weight in the previous year.

Although all women, obese and normal-weight, were premenopausal, none was pregnant or had been pregnant in the precedent 12 months. We considered only women who reported no previous diagnosis of any acute/chronic health condition (except obesity for the obese group). No woman was on any pharmacological regimen (except for oral contraceptives) or took any sporadic drug in the previous 7 days.

Obese women entered in a weight loss program and were re-assessed after a 6-month follow-up. 
The study was conducted following the approval of the institutional scientific and ethical boards according to the standards of the Declaration of Helsinki. Additionally, an informed consent was signed by all participants.

\section{Clinical Evaluation}

Each woman was characterized for total body weight, BMI, waist and hip circumferences, and for their ratio (waist-to-hip ratio). The body fat mass (absolute value and fat mass percentage of total body weight) was assessed by bioelectrical impedance (Tanita TBF-300A ${ }^{\circledR}$, Tanita Europe B.V., Hoofddorp, the Netherlands).

Blood pressure was assessed as the mean of two determinations at the left arm with a 5-min interval between, following the standard recommended procedures, by the use of an electronic device (CASMED $740^{\circledR}$ monitor, CAS Medical Systems Inc, Branford, CT, USA).

Obese women were submitted to a blood pressure and anthropometric reassessment after a 6-month follow-up in a weight loss program.

\section{Dietary Evaluation}

Each woman answered to a full detailed 24-hour food intake questionnaire, referring to an ordinary day. Each woman was asked to describe carefully all foods ingested considering the exact quantities. Women reported no significant inter-day variability. Questionnaires were analyzed in order to determine the total daily ingestion of carbohydrates, proteins, and fat as well as the total caloric intake.

The same questionnaire was applied to obese women after the 6-month follow-up.

\section{Blood Sample Collection and Measurements}

A venous blood sample was collected from patients and controls after overnight fasting. Serum samples were obtained by low-speed centrifugation, stored at a $-80 \stackrel{\circ}{\circ}$ ultra-freezer, and thawed just before each assay.

Biochemical parameters (glucose, triglycerides, total cholesterol, LDL-cholesterol, HDL-cholesterol) were determined by automated chemistry analyzer (Vitros ${ }^{\circledR}$ 5.1 FS Chemistry System, Ortho-Clinical Diagnosis Inc, Rochester, NY, USA). Insulin concentration was assessed by a chemiluminescent immunometric technique (IMMULITE ${ }^{\circledR} 2000$ Immunoassay System, Siemens Healthcare Diagnostics, Camberley, UK). Serum adiponectin, IL-6, and TNF- $\alpha$ concentrations were measured by enzyme-linked immunosorbent assay following the manufacturer's instructions (R\&D Systems Inc, Minneapolis, MN, USA). Insulin resistance was assessed by the homeostasis model assessment (HOMA-IR) using the formula: insulin $(\mu \mathrm{U} / \mathrm{ml}) \times$ glucose $(\mathrm{mg} / \mathrm{dl}) / 405$.

After the 6-month follow-up, a new fasting venous blood sample was collected from women in the obese group for assessment of the same parameters as in baseline.

\section{Statistical Analysis}

Data are reported as mean \pm SD. Comparisons between groups were made by Student's t-test. The interactions between non continuous parameters were analyzed by $\chi^{2}$ test.

Paired Student's t-test was used to compare the change observed over time in the analyzed parameters. Simple associations were tested by Spearman's r-test, and multiple regression analysis was carried out by the use of a forward stepwise model. A p value $<0.05$ was considered statistically significant. All determinations were performed using SPSS ${ }^{\circledR}$ software, version 18.0 (IBM Corporation, Armonk, NY, USA).

\section{Results}

The characterization of the obese and normal-weight groups is depicted in table 1 . Although no woman reported previous comorbidities, dysglycemia was present in 25 obese women at baseline evaluation (based on fasting or 2-hour oral glucose tolerance test glucose values). Obese women with dysglycemia presented lower levels of adiponectin when compared with normoglycemic (5.64 vs. $7.39 \mu \mathrm{g} / \mathrm{ml} ; \mathrm{p}=0.001$ ). 
Silva-Nunes et al.: Factors Related with Adiponectinemia in Obese and Normal-Weight Women and with Its Variation in Weight Loss Programs

Table 1. Baseline characterization of normal-weight and obese women groups (mean \pm SD)

\begin{tabular}{|c|c|c|c|}
\hline & Normal-weight women & Obese women & $\mathrm{p}$ value \\
\hline $\mathrm{N}$ & 100 & 112 & \\
\hline Age, years & $34.2 \pm 8.4$ & $34.6 \pm 8.3$ & 0.702 \\
\hline BMI, $\mathrm{kg} / \mathrm{m}^{2}$ & $21.4 \pm 1.7$ & $43.6 \pm 7.9$ & $<0.001$ \\
\hline Total body weight, kg & $56.0 \pm 5.3$ & $111.4 \pm 21.3$ & $<0.001$ \\
\hline Total body fat, kg & $14.3 \pm 3.6$ & $53.9 \pm 14.8$ & $<0.001$ \\
\hline Percentage of body fat, $\%$ & $25.3 \pm 4.7$ & $47.7 \pm 5.1$ & $<0.001$ \\
\hline Waist circumference, cm & $71.7 \pm 5.8$ & $117.5 \pm 15.1$ & $<0.001$ \\
\hline Hip circumference, $\mathrm{cm}$ & $97.4 \pm 4.5$ & $134.4 \pm 13.3$ & $<0.001$ \\
\hline Waist-to-hip ratio & $0.74 \pm 0.05$ & $0.88 \pm 0.07$ & $<0.001$ \\
\hline Adiponectin, $\mu \mathrm{g} / \mathrm{ml}$ & $11.9 \pm 5.09$ & $6.89 \pm 3.21$ & $<0.001$ \\
\hline IL-6, $\mathrm{pg} / \mathrm{ml}$ & $1.41 \pm 1.4$ & $2.43 \pm 1.67$ & $<0.001$ \\
\hline TNF- $\alpha, p g / m l$ & $1.30 \pm 0.78$ & $1.39 \pm 0.88$ & 0.445 \\
\hline Systolic blood pressure, mm Hg & $108.9 \pm 11.7$ & $124.4 \pm 16.3$ & $<0.001$ \\
\hline Diastolic blood pressure, $\mathrm{mm} \mathrm{Hg}$ & $69.2 \pm 9.4$ & $79.5 \pm 10.3$ & $<0.001$ \\
\hline Glucose, $\mathrm{mg} / \mathrm{dl}$ & $81.1 \pm 7.2$ & $93.4 \pm 28.6$ & $<0.001$ \\
\hline Insulin, $\mu \mathrm{UI} / \mathrm{ml}$ & $6.0 \pm 3.8$ & $17.6 \pm 11.2$ & $<0.001$ \\
\hline HOMA-IR & $1.21 \pm 0.76$ & $4.28 \pm 3.50$ & $<0.001$ \\
\hline $\mathrm{HbA1c} \%$ & $5.3 \pm 0.3$ & $5.6 \pm 0.8$ & $<0.001$ \\
\hline Total cholesterol, mg/dl & $173.6 \pm 28.3$ & $187.6 \pm 32.8$ & 0.001 \\
\hline LDL-cholesterol, mg/dl & $103.7 \pm 26.9$ & $120.2 \pm 27.1$ & $<0.001$ \\
\hline HDL-cholesterol, mg/dl & $66.3 \pm 13.8$ & $50.9 \pm 11.5$ & $<0.001$ \\
\hline Triglycerides, mg/dl & $79.0 \pm 29.1$ & $119.1 \pm 76.9$ & $<0.001$ \\
\hline High-sensitivity $\mathrm{C}$ reactive protein, $\mathrm{mg} / \mathrm{dl}$ & $0.22 \pm 0.31$ & $0.96 \pm 0.76$ & $<0.001$ \\
\hline Total daily caloric intake, kcal & $1,703 \pm 370$ & $1,610 \pm 564$ & 0.194 \\
\hline Daily intake of carbohydrates, $\mathrm{g}$ & $208.7 \pm 67.0$ & $185.0 \pm 69.1$ & 0.023 \\
\hline Daily intake of proteins, $g$ & $79.7 \pm 18.3$ & $76.0 \pm 23.4$ & 0.256 \\
\hline Daily intake of fat, $\mathrm{g}$ & $61.1 \pm 16.1$ & $62.8 \pm 27.2$ & 0.602 \\
\hline Women on oral contraceptives, $\%$ & 51.0 & 46.4 & 0.506 \\
\hline Active smoker, $\%$ & 34.0 & 11.6 & $<0.001$ \\
\hline
\end{tabular}

In the normal-weight group, an inverse correlation was present for adiponectin and TNF- $\alpha$ levels $(p=0.01 ; r=-0.255)$. Only in that group, adiponectin levels were significantly lower $(\mathrm{p}=0.041)$ in smokers (fig. 1$)$.

Adiponectinemia showed an inverse association with almost all anthropometric parameters in normal-weight women, but not in obese (table 2). In the normal-weight group we found by a stepwise analysis that a greater adjusted $r^{2}(0.436)$ was achieved if we considered a combination of five parameters: body fat percentage, waist-to-hip ratio, daily intake of carbohydrates, smoking, and TNF- $\alpha$ circulating levels.

From the total group of obese women, 96 (85.7\%) accomplished the 6-month reassessment. All of those women received appropriate lifestyle intervention. A 1,200 kcal/day hypolipidic, hypoglucidic diet was prescribed, and dietetic counseling was given monthly. An increase or decrease of $\pm 200 \mathrm{kcal} /$ day could be advised according to anthropometric evolution registered in the previous month. Due to the differences in the size of the gastric pouch, in women submitted to bariatric surgery a further decrease in food intake down to 800 $\mathrm{kcal} /$ day could be necessary. Every woman was advised to perform a regular continuous aerobic activity of at least $150 \mathrm{~min} /$ week, and accomplishment was supervised every month. 21 women were submitted to a bariatric procedure (adjustable gastric banding in 16 patients, sleeve gastrectomy in 4 and gastric bypass in 1). Additionally, some of the remaining 75 women have received pharmacological intervention with anti-obesity drugs, temporarily or during the entire follow-up period. 
Fig. 1. Adiponectin levels in obese and normal-weight women according to smoking status.

Silva-Nunes et al.: Factors Related with Adiponectinemia in Obese and Normal-Weight Women and with Its Variation in Weight Loss Programs

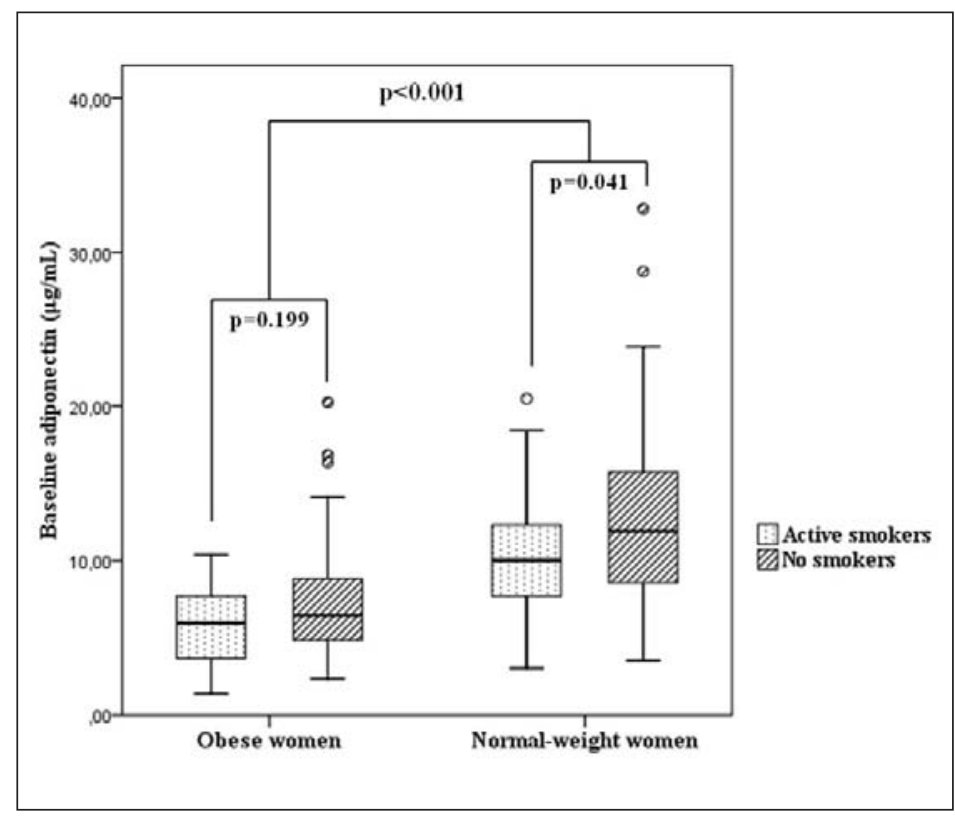

Table 2. Association between adiponectin circulating levels and anthropometric parameters in normalweight and obese women at baseline

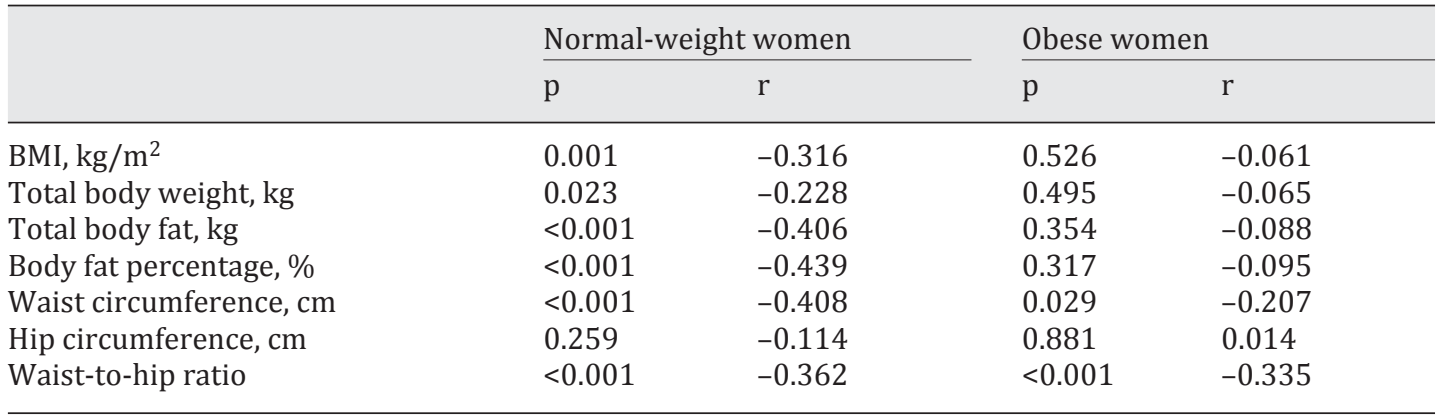

The $\mathrm{p}$ and $\mathrm{r}$ were obtained by Spearman analysis.

After 6 months of weight loss interventions, a significant increase in adiponectin circulating levels was registered in women both on surgical and non-surgical interventions (fig. 2).

Besides that adiponectin variation, a significant decrease in anthropometric parameters and a variation in diet macronutrients consumption were observed in both groups of intervention (table 3).

After adjustment to the baseline values, the variation in anthropometrics was more pronounced in those submitted to bariatric surgery $(\mathrm{p}<0.001$ for decreases in body weight and body fat percentage; $p=0.001$ for total fat and hip circumference; $p=0.003$ for waist circumference; $p=0.027$ for waist-to-hip ratio), but there is no significant difference in adiponectin variation between both types of intervention. No difference was found in the distribution of dysglycemic women between those submitted to surgical and those receiving nonsurgical interventions ( 23.8 vs. $27.3 \%$ ). The percentage of women achieving a $\geq 10 \%$ weight reduction was more significant $(\mathrm{p}<0.001)$ in those submitted to bariatric surgery compared 
Fig. 2. Variation in adiponectin circulating levels of obese women after 6 months in weight loss programs, according to surgical or non-surgical interventions.
Silva-Nunes et al.: Factors Related with Adiponectinemia in Obese and Normal-Weight Women and with Its Variation in Weight Loss Programs

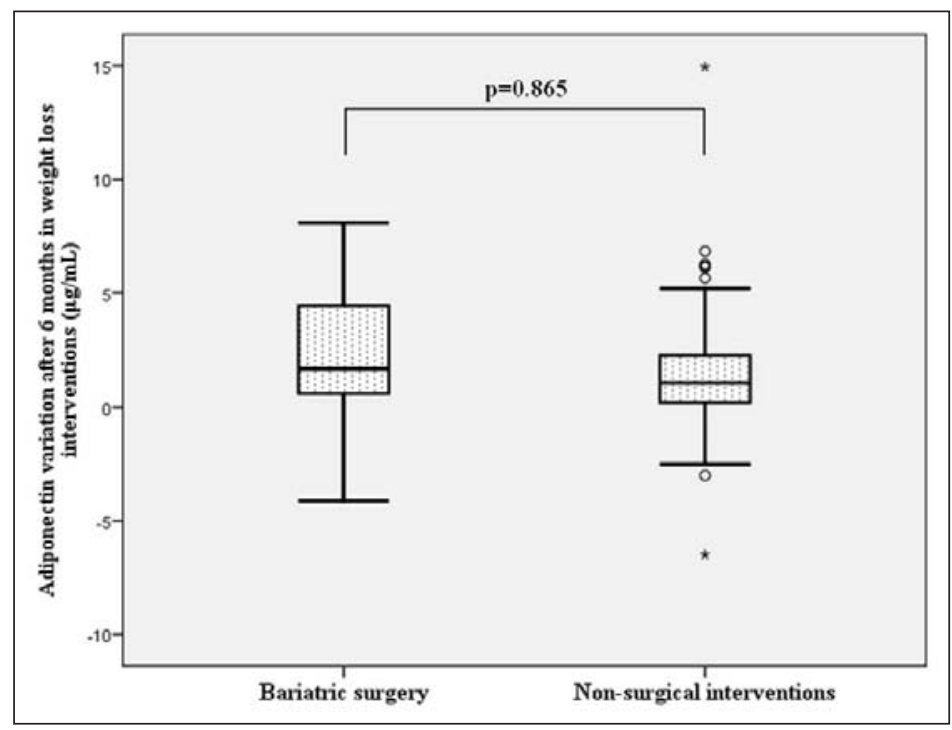

Table 3. Variation of parameters after 6 months, in women on surgical and non-surgical interventions

\begin{tabular}{|c|c|c|c|c|c|c|}
\hline & \multicolumn{3}{|c|}{$\begin{array}{l}\text { Women on bariatric surgery } \\
(\mathrm{n}=21)\end{array}$} & \multicolumn{3}{|c|}{$\begin{array}{l}\text { Women on non-surgical interventions } \\
(\mathrm{n}=75)\end{array}$} \\
\hline & $\begin{array}{l}\text { mean baseline } \\
\text { values }\end{array}$ & $\begin{array}{l}\text { mean month } 6 \\
\text { values }\end{array}$ & $\mathrm{p}$ & $\begin{array}{l}\text { mean baseline } \\
\text { values }\end{array}$ & $\begin{array}{l}\text { mean month } 6 \\
\text { values }\end{array}$ & $\mathrm{p}$ \\
\hline BMI, $\mathrm{kg} / \mathrm{m}^{2}$ & 46.5 & 39.2 & $<0.001$ & 43.2 & 41.5 & $<0.001$ \\
\hline Total body weight, kg & 116.9 & 98.4 & $<0.001$ & 109.9 & 105.6 & $<0.001$ \\
\hline Total body fat, kg & 57.5 & 43.5 & $<0.001$ & 52.9 & 49.7 & $<0.001$ \\
\hline Percentage of body fat, $\%$ & 48.6 & 43.6 & $<0.001$ & 47.6 & 46.5 & 0.008 \\
\hline Waist circumference, cm & 122.5 & 108.8 & $<0.001$ & 116.7 & 113.6 & $<0.001$ \\
\hline Hip circumference, $\mathrm{cm}$ & 138.0 & 126.4 & $<0.001$ & 134.0 & 130.6 & $<0.001$ \\
\hline Waist-to-hip ratio & 0.89 & 0.86 & 0.032 & 0.87 & 0.87 & 0.758 \\
\hline Adiponectin, $\mu \mathrm{g} / \mathrm{ml}$ & 6.91 & 9.21 & 0.002 & 7.06 & 8.51 & $<0.001$ \\
\hline IL-6, pg/ml & 2.29 & 2.72 & 0.517 & 2.51 & 2.93 & 0.151 \\
\hline $\mathrm{TNF}-\alpha, \mathrm{pg} / \mathrm{ml}$ & 1.35 & 1.91 & 0.128 & 1.33 & 2.02 & 0.22 \\
\hline Total daily caloric intake, kcal & 1749 & 1064 & 0.004 & 1635 & 1359 & 0.002 \\
\hline Daily intake of carbohydrates, $\mathrm{g}$ & 199.0 & 131.2 & 0.02 & 187.7 & 164.6 & 0.03 \\
\hline Daily intake of proteins, g & 82.5 & 58.6 & 0.025 & 78.2 & 67.4 & 0.02 \\
\hline Daily intake of fat, $g$ & 69.2 & 33.9 & 0.001 & 63.5 & 47.9 & $<0.001$ \\
\hline
\end{tabular}

with those in the non-surgical group (66.7 vs. $16.9 \%$ ). Only in those submitted to bariatric surgery, a significant difference $(\mathrm{p}=0.03)$ in adiponectin level increase was evident whether or not a $\geq 10 \%$ weight reduction was achieved.

In women submitted to a bariatric approach, an inverse correlation was observed between the absolute variation of adiponectin levels and the absolute variation in carbohydrate intake ( $\mathrm{p}=0.019 ; \mathrm{r}=-0.791)$ as well as the absolute variation in waist circumference ( $p=0.005 ; r=-0.59)$; by linear regression analysis considering both parameters, we obtained an adjusted $r^{2}=0.706$. If we consider the percentage variation of adiponectin circulating levels, a similar inverse association is present with the percentage variation in carbohydrate 
intake $(\mathrm{p}<0.001 ; \mathrm{r}=-0.835)$ and waist circumference $(\mathrm{p}=0.006 ; \mathrm{r}=-0.56)$. An adjusted $r^{2}=0.856$ is obtained by linear regression analysis taking into account these two parameters for the percentage of adiponectinemia variation.

\section{Discussion}

Adiponectin is a very important adipokine for metabolic and cardiovascular protection. Every intervention that results in an increase in adiponectin circulating levels is expected to induce a positive health increment $[19,20]$. In accordance with previous data, we found lower levels of adiponectin in the obese women and, in this group, in those who were diagnosed with dysglycemia [21].

Inconsistent to what is usually reported $[22,23]$, we found no difference in TNF- $\alpha$ or IL-6 between obese and normal-weight women. Although being obese, the women in the obese group entered the study with no other known comorbidity. Perhaps that could explain the absence of significantly higher levels of these two adipokines. Another explanation could be related to caloric and macronutrients intake [24]. The authors are aware of the accuracy limitations of a food questionnaire based on a single day. However, the food intake descriptions were carefully detailed. No difference was seen for caloric intake between groups, and normalweight women had even reported a higher daily intake of carbohydrates than obese women. Moreover, no association was found between carbohydrate intake and IL- 6 or TNF- $\alpha$ circulating levels. Obviously, once we are based in self-reported data, it is possible that some bias exist between data from the food intake questionnaire and what is the regular ingestion for each participant.

In normal-weight women, smoking has a deleterious effect on adiponectin circulating levels which is in accordance to previous data [25]. However, this is not observed in the obese group, perhaps because the prevalence of smokers is far less than in the control group. In this group, TNF- $\alpha$ circulating levels are inversely associated with adiponectinemia which is in accordance with the effect of adiponectin gene down-regulation by TNF- $\alpha$ [11]. The fact that this phenomenon does not occur in the obese group is unexpected and could not be explained by the parameters considered in this study.

Abdominal fat mass, in obese women, and all anthropometric parameters (except hip circumference), in normal-weight women show an inverse association with adiponectin circulating levels in accordance to previous data [26]. Opposite to obese women whose abdominal fat mass parameters explain about $10 \%$ of adiponectinemia, in normal-weight women anthropometrics, daily intake of carbohydrates, smoking, and TNF- $\alpha$ circulating levels explain nearly $50 \%$ of adiponectin circulating levels. Therefore, the regulation of total adiponectin levels is slightly explained by the parameters considered in this study. Although there is an association between the total and the HMW form of adiponectin, perhaps, if HMW adiponectin is considered, a more consistent explanation for the regulation of its circulating levels could be found $[27,28]$.

Bariatric surgery is more efficacious for weight loss than non-surgical interventions, especially in severely obese patients [29]. This conclusion was also drawn from this study, with a more pronounced decrease for all anthropometric parameters in those submitted to a bariatric intervention than in those on non-surgical approaches.

It has been described that a significant weight loss can decrease pro-inflammatory cytokine levels, namely TNF- $\alpha$ and IL-6 [30]. However, in this study no difference was registered for the circulating levels of those two cytokines after weight loss interventions, as shown by others [31]. This finding could not be explained by the variation observed in anthropometrics or in daily caloric intake or macronutrient content variations. 
As described in the literature, an increase in adiponectin circulating levels was observed with weight loss interventions [32]. Although a significantly greater reduction in anthropometrics occur in those women on a bariatric approach, the increase in adiponectin circulating levels showed no difference between surgical and non-surgical weight loss interventions. In obese women on non-surgical interventions, the variation observed in adiponectin circulating levels shows no parallelism with the variation registered in the parameters considered. However, in those submitted to a bariatric procedure, a parallelism is already evident with the variation observed in anthropometrics and carbohydrate intake; that explains more than two thirds of the variation observed in adiponectinemia. In concordance to previous data, it seems necessary that a significant amelioration in anthropometrics occur in order to induce a significant change in adiponectinemia [33]. Women submitted to the bariatric procedures were more successful in achieving a more than 10\% weight loss after 6 months (66.7 vs. $16.9 \%)$. Considering the bariatric group, those who have achieved that weight loss had a more pronounced increase in adiponectinemia. Although no significant difference in the variation of carbohydrate intake is seen between surgical and non-surgical groups, in the group submitted to bariatric surgery the variation that occurred in carbohydrate intake is the main determinant of adiponectinemia variation (independently from the subsequent variation in anthropometrics). This finding highlights the role of diet's macronutrient composition on the adipokines' profile of obese patients independently from its known effect on the regulation of body fat mass.

\section{Conclusion}

There is an inverse association between circulating adiponectin and anthropometric parameters both in obese and normal-weight women. Dysglycemia was associated with lower adiponectin levels in the obese. Smoking is a deleterious conditioning factor for adiponectinemia in normal-weight women. Although there is evidence that anthropometric parameters, smoking, daily carbohydrate intake, and TNF- $\alpha$ levels all influence adiponectinemia, they explain less than $50 \%$ of total adiponectin concentration in normal-weight women. In obese women, adiponectin is minimally associated with those factors, and anthropometrics (mostly the pattern of fat distribution) explain less than $10 \%$ of its circulating levels. Although an increase in adiponectin circulating levels occurs after surgical and non-surgical weight loss interventions, only in women submitted to bariatric surgery (those with a more pronounced reduction in anthropometric parameters) an inverse parallelism of adiponectinemia variation with diet composition and anthropometric changes is evident. Taken together, the changes in those two parameters observed after 6 months largely explain the variation in adiponectin circulating levels registered in that group.

\section{Funding}

This work was funded by a Merck Portugal and by an Abbott/ Portuguese Society of Endocrinology, Diabetes and Metabolism grants for investigation in obesity.

\section{Disclosure Statement}

The authors declare no conflict of interest in the area. 
Silva-Nunes et al.: Factors Related with Adiponectinemia in Obese and Normal-Weight Women and with Its Variation in Weight Loss Programs

\section{References}

1 Tilg H, Moschen AR: Adipocytokines: mediators linking adipose tissue, inflammation and immunity. Nat Rev Immunol 2006;6:772-783.

-2 Kadowaki T, Yamauchi T: Adiponectin and adiponectin receptors. Endocr Rev 2005;26:439-451.

$\checkmark 3$ Scherer PE: Adipose tissue: from lipid storage compartment to endocrine organ. Diabetes 2006;55:15371545.

4 Zhu W, Cheng KK, Vanhoutte PM, Lam KS, Xu A: Vascular effects of adiponectin: molecular mechanisms and potential therapeutic intervention. Clin Sci (Lond) 2008;114:361-374.

-5 Hivert MF, Manning AK, McAteer JB, Florez JC, Dupuis J, Fox CS, O’Donnell CJ, Cupples LA, Meigs JB: Common variants in the adiponectin gene (ADIPOQ) associated with plasma adiponectin levels, type 2 diabetes, and diabetes-related quantitative traits: the Framingham Offspring Study. Diabetes 2008;57:3353-3359.

-6 Fredriksson J, Carlsson E, Orho-Melander M, Groop L, Ridderstråle M: A polymorphism in the adiponectin gene influences adiponectin expression levels in visceral fat in obese subjects. Int J Obes (Lond) 2006;30:226-232.

7 Han SH, Sakuma I, Shin EK, Koh KK: Antiatherosclerotic and anti-insulin resistance effects of adiponectin: basic and clinical studies. Prog Cardiovasc Dis 2009;52:126-140.

-8 Yamauchi T, Kadowaki T: Physiological and pathophysiological roles of adiponectin and adiponectin receptors in the integrated regulation of metabolic and cardiovascular diseases. Int J Obes (Lond) 2008;32(suppl 7):S13-18.

9 Cook JR, Semple RK: Hypoadiponectinemia - cause or consequence of human 'insulin resistance'? J Clin Endocrinol Metab 2010;95:1544-1554.

$\checkmark 10$ Bruun JM, Lihn AS, Verdich C, Pedersen SB, Toubro S, Astrup A, Richelsen B: Regulation of adiponectin by adipose tissue-derived cytokines: in vivo and in vitro investigations in humans. Am J Physiol Endocrinol Metab 2003;285:E527-533.

11 Li L, Yang G, Shi S, Yang M, Liu H, Boden G: The adipose triglyceride lipase, adiponectin and visfatin are downregulated by tumor necrosis factor-alpha (TNF-alpha) in vivo. Cytokine 2009;45:12-19.

-12 Maeda N, Takahashi M, Funahashi T, Kihara S, Nishizawa H, Kishida K, Nagaretani H, Matsuda M, Komuro R, Ouchi N, Kuriyama H, Hotta K, Nakamura T, Shimomura I, Matsuzawa Y: PPARgamma ligands increase expression and plasma concentrations of adiponectin, an adipose-derived protein. Diabetes 2001;50:20942099.

13 Summer SS, Brehm BJ, Benoit SC, D’Alessio DA: Adiponectin changes in relation to the macronutrient composition of a weight-loss diet. Obesity (Silver Spring) 2011;19:2198-2204.

14 Yeung EH, Appel LJ, Miller ER 3rd, Kao WH: The effects of macronutrient intake on total and high-molecular weight adiponectin: results from the OMNI-Heart trial. Obesity (Silver Spring) 2010;18:1632-1637.

$\checkmark 15$ Schwarz PE, Towers GW, Fischer S, Govindarajalu S, Schulze J, Bornstein SR, Hanefeld M, Vasseur F: Hypoadiponectinemia is associated with progression toward type 2 diabetes and genetic variation in the ADIPOQ gene promoter. Diabetes Care 2006;29:1645-1650.

16 Ohashi K, Ouchi N, Matsuzawa Y: Adiponectin and hypertension. Am J Hypertens 2011;24:263-269.

17 Kumada M, Kihara S, Sumitsuji S, Kawamoto T, Matsumoto S, Ouchi N, Arita Y, Okamoto Y, Shimomura I, Hiraoka H, Nakamura T, Funahashi T, Matsuzawa Y; Osaka CAD Study Group: Coronary artery disease association of hypoadiponectinemia with coronary artery disease in men. Arterioscler Thromb Vasc Biol 2003;23: 85-89.

-18 Valsamakis G, McTernan PG, Chetty R, Al Daghri N, Field A, Hanif W, Barnett AH, Kumar S: Modest weight loss and reduction in waist circumference after medical treatment are associated with favorable changes in serum adipocytokines. Metabolism 2004;53:430-434.

-19 Xu A, Wang Y, Lam KS, Vanhoutte PM: Vascular actions of adipokines molecular mechanisms and therapeutic implications. Adv Pharmacol 2010;60:229-255.

20 Antonopoulos AS, Lee R, Margaritis M, Antoniades C: Adiponectin as a regulator of vascular redox state: therapeutic implications. Recent Pat Cardiovasc Drug Discov 2011;6:78-88.

-21 Cnop M, Havel PJ, Utzschneider KM, Carr DB, Sinha MK, Boyko EJ, Retzlaff BM, Knopp RH, Brunzell JD, Kahn SE: Relationship of adiponectin to body fat distribution, insulin sensitivity and plasma lipoproteins: evidence for independent roles of age and sex. Diabetologia 2003;46:459-469.

-22 Bastard JP, Maachi M, Lagathu C, Kim MJ, Caron M, Vidal H, Capeau J, Feve B: Recent advances in the relationship between obesity, inflammation, and insulin resistance. Eur Cytokine Netw 2006;17:4-12.

23 Galic S, Oakhill JS, Steinberg GR: Adipose tissue as an endocrine organ. Mol Cell Endocrinol 2010;316:129-139.

-24 Arvidsson E, Viguerie N, Andersson I, Verdich C, Langin D, Arner P: Effects of different hypocaloric diets on protein secretion from adipose tissue of obese women. Diabetes 2004;53:1966-1971.

-25 Bergmann S, Siekmeier R: Influence of smoking and body weight on adipokines in middle aged women. Eur J Med Res 2009;14(suppl 4):21-26.

26 Kishida K, Kim KK, Funahashi T, Matsuzawa Y, Kang HC, Shimomura I: Relationships between circulating adiponectin levels and fat distribution in obese subjects. J Atheroscler Thromb 2011;18:592-595.

27 Nakashima R, Yamane K, Kamei N, Nakanishi S, Kohno N: Low serum levels of total and high-molecular-weight adiponectin predict the development of metabolic syndrome in Japanese-Americans. J Endocrinol Invest 2011;34:615-619. 
Silva-Nunes et al.: Factors Related with Adiponectinemia in Obese and Normal-Weight Women and with Its Variation in Weight Loss Programs

28 Hirose H, Yamamoto Y, Seino-Yoshihara Y, Kawabe H, Saito I: Serum high-molecular-weight adiponectin as a marker for the evaluation and care of subjects with metabolic syndrome and related disorders. J Atheroscler Thromb 2010;17:1201-1211.

-29 Martins C, Strømmen M, Stavne OA, Nossum R, Mårvik R, Kulseng B: Bariatric surgery versus lifestyle interventions for morbid obesity-changes in body weight, risk factors and comorbidities at 1 year. Obes Surg 2011; 21:841-849.

30 Moschen AR, Molnar C, Geiger S, Graziadei I, Ebenbichler CF, Weiss H, Kaser S, Kaser A, Tilg H: Anti-inflammatory effects of excessive weight loss: potent suppression of adipose interleukin 6 and tumour necrosis factor alpha expression. Gut 2010;59:1259-1264.

31 Pardina E, Ferrer R, Baena-Fustegueras JA, Rivero J, Lecube A, Fort JM, Vargas V, Catalán R, Peinado-Onsurbe J: Only C-reactive protein, but not TNF- $\alpha$ or IL6, reflects the improvement in inflammation after bariatric surgery. Obes Surg 2012;22:131-139.

32 Forsythe LK, Wallace JM, Livingstone MB: Obesity and inflammation: the effects of weight loss. Nutr Res Rev 2008;21:117-133.

33 Varady KA, Tussing L, Bhutani S, Braunschweig CL: Degree of weight loss required to improve adipokine concentrations and decrease fat cell size in severely obese women. Metabolism 2009;58:1096-1101. 